\title{
Some Socio-Economic and Demographic Characteristics of Parents/Caregivers and Implication on Birth Registration Coverage in Gombe State, Nigeria.
}

\author{
Abbas, Adam M. (PhD) \\ National Population Commission, 17 Ibrahim Dabo Rd. P.M.B. 3199, Kano, Kano-State, Nigeria.
}

\begin{abstract}
This study is designed to assess some Socio-economic and demographic characteristics of parents/caregivers such as age, sex, marital status, religion, occupation, educational background and residential ownership status (independent variables) and their influence on birth registration (dependent variable) coverage in Gombe State. The findings were based on primary data sourced from the field through questionnaire survey, interview and field observation and secondary data on population, localities and registered live-birth data collected from the National Population Commission for a period of eight years (20002008). A total of 1530 respondents who were heads of households and parents/caregivers of eligible/registerable children aged 0-20 years were interviewed. It was conceptually hypothesized that the independent variables have influence on the dependent variable. Use was made of $\chi^{2}$ tests, percentages and cross tabulations in an attempt to analyze the influence. The analysis of the data revealed that, almost all the respondents were males and married. The paper further observed that all the independent variables with the exception of sex and marital status are found to have significant influence on the dependent variable. It is therefore suggested that for birth registration system to be effective, permanent and sustained a long term approach such as its integration into immunization and other early child development programmes are needed alongside aggressive enlightenment campaigns to be undertaken by all the principal stakeholders and to be directed mainly towards the rural areas. More registration centres should also be established in the nucleus of rural population.
\end{abstract}

Keywords: Socio-Economic, Demographic, Parents, Caregivers, Birth Registration, Coverage.

\subsection{Background to the Study}

\section{Introduction}

Nigeria is a signatory to international treaties, which emphasize the right of every child at birth, to acquire a name and nationality and the establishment of the civil registration system in the country is her strategic response to them. ${ }^{[1],[2], ~[3]}$. Birth registration is part of an effective civil/vital registration system that legally acknowledges the existence of the person, enables child to obtain a birth certificate whose issuance automatically follows the registration, establishes the child's family ties, and tracks the major events of an individual's life from live births to marriages and deaths. ${ }^{[4], ~[5], ~[6], ~[7], ~[8], ~[9] ~}$

In Nigeria, with the development of strategy document that covers the period 2008-2015, the goal of the National Population Commission is $60 \%$ by 2010 and $100 \%$ by 2015 in line with the United Nation's Millennium Development Goals (MDGs) set target. With only two centres per local government which in some places are poorly located since they are mostly sited at public health centres which themselves have irregular distribution throughout the developing world according to ${ }^{[10]}$ and $\left.{ }^{[11}\right]$ the level of birth registration has been low. The degree of coverage is still very low, just in the range of $2 \%$ to $20.6 \%{ }^{[12]}$. Even UNICEF suggested that, necessary infrastructure to reach the entire population should be put in place if the target is to be met; otherwise, ' $100 \%$ coverage' will remain a distant reality ${ }^{[13]}$.

In fact, the problems of vital registration are complex and have hindered many citizens from going to register in the vital registration centres in Gombe State. Hence, there has been low coverage in many parts of the state.

Generally, a lot of factors have been identified as having influence on birth registration but the magnitude of the effects has not been sufficiently discussed. More so, there has been much push of blame on the government alone and the earlier studies are also constrained by looking at the problems from larger perspectives (global). Thus, the effects of socio-economic and demographic characteristics of parents/caregivers have been given less attention especially on a local-specific basis. Also, currently our knowledge is limited concerning which of the factors significantly affect birth registration. ${ }^{[5]}$ therefore, stated that partners working in the area of birth registration should note that achieving complete birth registration levels depends on more than just the commitment of governmental agencies and national policies. Whether a father or a mother registers the 
birth of his or her child depends on the level of awareness of the process, its importance, the ability to access civil registrar services, and the willingness to interface with state authorities. ${ }^{[14],[8]}$

This study would therefore be of great import to the realization of not only the influence of parents' background characteristics on birth registration coverage but also on how to tackle some of the problems suffered by the registration system. The study has as a main aim the examination of whether parents'/guardians' socio-economic and demographic characteristics influence registration of birth or not establishment of a system of birth registration that is permanent and sustained is therefore necessary if the set target is to be met. In the words of ${ }^{[5]}$ it is essential to create an effective 'supply' of birth registration services, backed by the stimulation of informed 'demand'.

The importance of the system has led to the recognition of the numerous problems facing the registration system. The relationship between some parents' background characteristics and birth registration is evident given various studies that abound. For instance, ${ }^{[4]}$ study of the global causes of poor registration showed that, the main challenge to birth registration is that it is not universally perceived as a fundamental right and as result; it is given a low priority at every level. This study was collaborated by ${ }^{5]}$ which used data from different countries of the world. ${ }^{[15]}$, s study aiming at identifying good practices led by UNICEF between 2000-2009 in integrating birth registration with the health system in some specified countries stated that the unregistered children are almost always from poor, socially excluded or displaced families, and often have illiterate parents or live in countries where registration systems either not in place or not functional. Various studies such as those undertaken by ${ }^{[13],[6]}$ and ${ }^{[8]}$ have also found varying degree of the barrier effects on birth registration.

A number of studies have indicated the effect of geographic barrier rather than other factors relating to

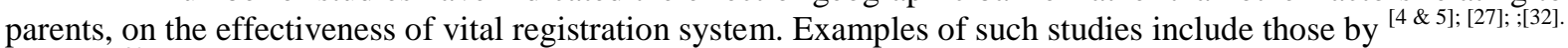
In fact, ${ }^{[32]}$ applied GIS in assessing existing birth registration centres in Gombe LGA. The study was however restricted to Gombe LGA which is an urban setting and the GIS application too was limited to locating the registration centres for easy access and retrieval of information only. Also, ${ }^{[11]}$ has applied GIS to study hospital availability and accessibility in Gombe LGA.The quantification and understanding of such effects were however, not treated anywhere in detail. Hence, there is a knowledge gap in this regard, more especially, in terms of the magnitude of the effect of distance in a particular area.

Specifically, the following constitute the objectives of the study:-identifying those characteristics that significantly affect the registration; suggesting ways by which birth registration can be made efficient and effective. These were carried out in order to answer the following questions: do the parents'/care givers' socioeconomic and demographic characteristics have influence on children's registration of births significantly? Which of the socio-economic and demographic characteristics of parents significantly influence birth registration in the study area?

Any study that could bring out the more serious challenges facing the system and the planning techniques for improvement should be given the deserved consideration. UNICEF supports countries to collect information on the situation of children and women through the MICS programmes and one of them is birth registration. However, UNICEF is always concern with only children of 0-5 years. It is as a result of all these that the study tries to investigate the significant relationship between some of the socio-economic and demographic characteristics of parents in Gombe state and registration of birth.

It is the purpose of this study to identify and ascertain problems militating against effective birth registration with a view to make appropriate recommendations for improved and efficient birth registration coverage. Thus, those demographic and socio-economic characteristics of the people capable of influencing birth registration coverage are also given according to the magnitude of their effects.

This research is significant because the results will assist population planners and policy makers in the National Population Commission and Gombe State Government to achieve their goal of 100\% coverage of the vital events by the year 2015. This Second, since no one doubts the fact that vital statistics as computable from registration of important events (especially births and deaths), constitute an important set of data for studying the dynamics of a country's population, it is believed that a study of this nature will play a very important role in the field of population study. It would also serve as a handbook not only to scholars but also students in that field.

\subsection{The Study Area}

The study area is Gombe State (figure 1). Six LGAs which cumulatively have land area of 8 , $872.55 \mathrm{~km}^{2}(43.785 \%$ of the state's land mass) constitutes the sampled area. The State has a projected population for 2010 of 2,653,806 with 1,396,146 males and 1,257,661 females ${ }^{[16]}$. The sampled LGAs are Akko, Balanga, Billiri, Gombe, Nafada and Yamaltu-Deba with 2010 projected population of 1,587,050 having 839,538 males and 747,512 females. 


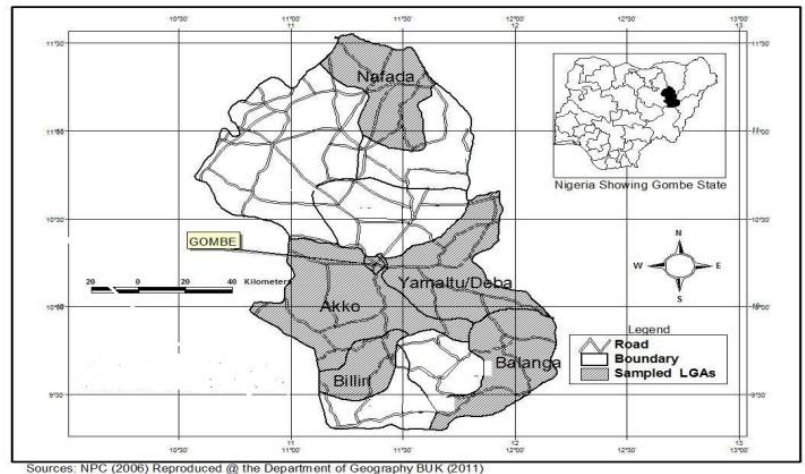

Fig. 1: Gombe State Showing Sampled LGAs

\subsection{Conceptual Framework}

\section{Conceptual And Theoretical Frameworks}

Conceptually, it has been hypothesized that Parents' socio-economic, demographic characteristics affect birth registration of their children. Thus, the major barriers to birth registration commonly reported in the literature are social, economical and geographical.

The relationship between child's birth registration and socio-economic and demographic characteristics of the child's family can be conceptualized at a fairly general level in fig. 2. As a two stage relationship a set of causal factors (Independent) impact on a series of outcomes (Dependent variables) including the child' birth registration. Intervening variables sometimes serve as intermediaries or impetus to the registration, making it a three stage relationships. Thus, it is recognized that a policy change such as aggressive enlightenment campaigns especially one directed towards the rural areas for creation of awareness on the importance of birth registration as well as integration of the registration into routine immunization and other early child development programmes can result in quite a different outcomes as they would serve as modifying factors. Also having a strong political will by the governance and a strong legal frame work could make the system work better ${ }^{[4] ;[5] ;[2]}$ and ${ }^{[17]}$ The following are the variables:

a.) Independent Variables (Causal Factors)

In Column 'a' of the diagram, examples of Parent's background characteristics which include: sex, age, marital status, housing tenancy, occupation (proxy for income sources), rural or urban, educational level and type etc and some factors external to them but which influence registration of births are listed. Thus, they can all be considered to be sometimes directly impacting on the dependent variables in column ' $c$ ' of the diagram.

b.) Intervening Variables (Intermediaries)

Column ' $b$ ' of the diagram reflects the factors that may influence the impact of the independent variables. Thus, it contains a set of parameters that can modify the negative impact of the independent variables on the dependent variables. They therefore, serve as intermediary influencing factors as result of which the independent variables could impact positively on the dependent variables. For example, once there are incentives, easy access to the facility through more centres or active method, law compelling people to register and/ or creation of awareness on the importance of the registration parents are likely to register the births of their children en mass ${ }^{[18] ; ~[19] . ~}$

c.) Dependent Variables (Outcomes)

The dependent variables indicated in column ' $c$ ' are the expected outcome whose occurrence depends on the independent variables or needs the intervening variables to modify the negative impact of the socio-economic and demographic variables (independent variables). However, only single dependent variable is used in this study that is, the registration of births. 
a.)Independent Variables $\quad$ b.)Intervening Variables

\begin{tabular}{|l|l|}
\hline Parent's residential. sector & \\
Parent's Sex & $\begin{array}{l}\text { Parent's Age } \\
\text { Parent's Marital Status } \\
\text { Parent's Religion } \\
\text { Parent's Ethnic Group } \\
\text { Parent's Nationality } \\
\text { Parent's state /Geo pol. zone of origin } \\
\text { Parent's Type \& level of education } \\
\text { Parent's Occupational Status \& Type } \\
\text { Parent's Status of Owner ship of Residence } \\
\text { (Accessibility) } \\
\text { Active method/mob-up of } \\
\text { birth } \\
\text { registration/integration into } \\
\text { immunization }\end{array}$ \\
\hline
\end{tabular}

Figure 2: Conceptual Framework.

\subsection{Theoretical Framework}

According to ${ }^{[20]}$ and ${ }^{[21]}$, the notion of Cause-and- Effect Model has been extremely important in the history of scientific investigation. While, it has around it so much contentious arguments it still provides us with useful model for analyzing geographic problems. The problem of applying cause-and-effect logic in empirical research boils down to one of identifying the variables which are causally related and identifying the boundaries of the system within which we can apply cause-and effect analysis. The general application of cause-and effect analysis also involves definition of appropriate sets of events.

In all this we have accepted the idea that one variable could be described as the cause of changes in another. Cause -and-effect relationship is normally stated in the form: if $\mathrm{X}$ happens then $\mathrm{Y}$ is always produced by it or if ' $\mathrm{X}$ then $\mathrm{Y}$ '. We are often faced with a chain of relationship.

Based on the objective, we are interested on only one dependent variable (effect) and many independent variables (causes) and multivariate analysis is more appropriate. Hence, as ${ }^{[22]}$ stated, "it is possible to extend chi-square $\left(\chi^{2}\right)$ analysis to situations in which individual independent mainly nominal variables are used to account for variability of a single response (dependent) variable'. Where, registration of birth is the Dependent Variable and the parent's socio-economic and demographic characteristics as well as distance are the Independent Variables.

\subsection{Model Specification for the Socio-Economic and Demographic Effects}

The $\chi^{2}$ test is widely used for the purpose of seeing whether a particular probability distribution is a good model for the sampled population. According to ${ }^{[22]}$, the judgment is made according to whether the probability distribution specified by the null hypothesis provides a good fit for the sample data.

This $\chi^{2}$ tests whether the observed frequencies of a given phenomenon differ significantly from the frequencies which might be expected according to some assumed hypothesis.

The $\chi^{2}$ test is based on a comparisonof the observed frequencies ' $f_{i}$ ', and the expected frequencies ' $F_{j}$ '. The closer the set of $f_{i}$ to $F_{j}$, the more likely it is that the distribution of the sample reflects the probability specified in the null hypothesis. The farther apart the observed and expected frequencies are, the less likely $H_{o}$ is true. The test statistic is therefore the sum of the relative squared difference. In other words, for each category the amount by which the observed frequency differs from the expected frequency is squared, and then related to the expected frequency itself as shown in equation (1) below: 


$$
\chi^{2}=\sum_{i=j}^{k} \frac{\left(f_{i}-F_{j}\right) 2}{F_{j}} \operatorname{or} \chi^{2}=\sum \frac{(O-E) 2}{E}
$$

\section{Research Materials And Methods}

\subsection{Types and Sources of Data}

This study is based on birth registration data for eight years (2000-2008) collected from National Population Commission and data derived through interviewing parents/caregivers and other stakeholders. As rightly stated by ${ }^{[25]}$, 'the essence of interviewing is tact, both in what is said and done.' The interviewees were therefore either met in their homes or offices by the interviewers.

To achieve the stated objectives of this study, two major sources of data were identified and explored. They are namely: primary and secondary sources.

i) Other primary data like the independent variables (fig. 2) for this study were obtained from the field through questionnaire administration and interviews. Additional primary data were collected from the field through direct field observation (DFO) and in-depth interview.

ii) The secondary data that were used are topographic, administrative and road maps, locality gazetteer as well as the 1991 population of all the localities and birth records were all obtained from the National Population Commission and projected by the researcher. The 1991 locality population figures were used because those for 2006 were yet to be released by the Commission as at the time of the survey. Other secondary data were obtained from library research and internet.

\subsection{Interview: Sampling Frame and Methods}

A probability sampling procedure was adopted in selecting respondents for the study using a complex sampling design that involved multi-stage stratified sampling procedure. This enabled us generate quantitative data for this study. Apart from the probability and advantage of this sampling technique to this study it also assists in assuring that all possible categories of respondents are considered [22]; [26].

The study covers six (6) out of the eleven (11) LGAs of Gombe State. Two LGAs were randomly selected from each of the 3 senatorial districts. The sampled LGAs are namely: Akko, Balanga, Billiri, Gombe, Nafada and Yamaltu-Deba. They represent about 55 percent of the total number of 11 LGAs in the State and have estimated population of about 1,587,050. The selected LGAs are also heterogeneous in terms of landscape, culture and religion. Thus, the units were selected in such a way that they provide fair representation of all the cultural and ethnic set-ups. Three political wards were further randomly selected from each LGA. This was followed by stratified and purposive selection of four (4) localities from each ward (1-urban; 3-rural), including all the localities where registration centres exist. At this level, urban sector is defined as a locality with a population size of 20,000 or above.

Within each LGA, clusters equivalent to the number of the selected localities were systematically selected, using the Enumeration Area (EA) map and list for each LGA. Localities from each of the wards of the selected LGAs were stratified according to their sectoral locations (urban and rural), sizes in terms of population, and distance from registration centres using projected population, locality lists and road map as frames of reference. Thus, for each rural and urban sector of a ward, four (4) clusters were allocated to the sampled localities. All the localities that belong to each of the sampled wards were arranged according to their geographic locations with their projected population attached.

The next stage was the collation of the census Enumeration Areas (EAs)- small subdivisions carved out of localities for the purpose of census and surveys of localities. For the purpose of this study, EAs equivalent to the number of clusters allocated to the localities were systematically selected. Twelve (12) EAs were selected in each sampled LGA. Thus, a total of 72 EAs were systematically sampled from the EAs of the affected localities in the first instant. The number of EAs allocated however, increased for a locality where the number of eligible respondents for sampled EA is below what was required. Likewise, the number of the localities increased in some localities in rural sectors whose allocated EAs happened to be multi-locality EAs.

Interview schedules were administered on Parents of children from age bracket of one (1) to eighteen (18) years. A total of 85 respondents from each of the three selected wards in each LGA were interviewed. For each of the nine (9) rural clusters in an LGA, 20 respondents, i.e. 180 rural respondents and 25 respondents from each of the 3 urban clusters (including the localities where vital registration centres exist) - i.e. 75 urban respondents were interviewed in an LGA. Therefore, 255 instruments were administered on the sampled respondents from twelve (12) localities in each LGA. A total of about 1,530 respondents were therefore interviewed in the whole of the state and same number analyzed. All the respondents' communities were classified according to their proximity to registration centers. 
Using the topographic and administrative maps of the study area as the frame of reference the samplings were made to cut across the whole extent of the study area. The respondents were then randomly selected from each of the at least ten (12) localities in each local government area (i.e. based on the population sizes of the localities and the LGAs as well as their distances from registration centres). This method also enabled us ascertain the spread of impact of the registration system.

\subsection{Methods and Techniques of Data Presentation and Analysis:}

In the analysis of socio-economic profiles of parents /caregivers, factors such as sex, age, marital status, nationality, state of origin, type and status of education, type of education and ownership of a house amongst others were considered as independent variables and cross-tabulated with birth registration (dependent variable).

Analyses of the data also include a description of the study population followed by cross tabulations and bivariate analysis of chi-square among all the categories of independent variables and the dependent variables.

\section{Results And Discussions}

\subsection{Socio-Economic and Demographic Characteristics of the Respondents}

The responses for this section were gathered through interview schedule and questionnaire. The respondents were heads of households or parents/guardians or care givers of children whose births were supposed to have been registered with the National Population Commission. It is believed that these independent variables influence birth registration. The socio-economic and demographic characteristics of the respondents are hereby explained as follow:

Parents' Sex

Age and sex are important demographic variables and the primary basis of demographic classification ${ }^{[23] \text {; }}$ [24] Table 9 shows the percent distribution of interviewed respondents (heads of households) by sex at the time of the survey. There is preponderance of male heads of house-holds over females. Thus, 9 in 10 of the respondents are males and only 1 in 10 of them is females. This happened because there were more male heads of house-holds than females in the state. The registration of child's birth is the responsibility of such persons and normally in this part of the country males are expected to be more concerned.

\section{Parents’ Age Groups}

In terms of age structure of the respondents, older adult group aged (40-59) leads as heads of households for this survey, followed by younger adult. The youth group is the last, while the aged group occupies the third position. The frequencies and percent distribution are shown in table 1. As a matter of fact, the older adult group is the most fertile and economically active population in every society and at that age most of the members of the group are married with children.

\section{Parents' Marital Status}

Table 1 further shows the percent distribution of respondents by marital status at the time of the survey. The predominance of married people as respondents may not be unconnected with fact that marriage is one of the primary indicators of being a responsible person so as to even serve as a heads of households. Widow as head ranks the least because in most cases children of deceased persons are parented by their male relations.

\section{Parents' Religious Affiliation}

1 which shows the respondents' religions indicates that Muslims constitute over 7 in 10, followed by Christians about 2 in 10 and the traditional religion (less than 1 in 10). This situation can be explained by the fact that Muslims were in majority in state at the time of the survey. The influence of this situation on birth registration is discussed in the next section.

Parents' Ethnic Group/Tribe

Table 1 shows that the four major ethnic groups namely: Tangale, Fulani, Tera and Waja outnumber the other ethnic groups, in terms of being respondents to the interview during the survey. They cumulatively constitute three-quarters of all the respondents, with Fulani taking the lead by having about one-third.

TABLE 1: Demographic Characteristics of Respondents

\begin{tabular}{|l|l|l|}
\hline Sex & Frequency & Percent \\
\hline Male & 1512 & 98.8 \\
\hline Female & 18 & 1.2 \\
\hline Total & 1530 & 100 \\
\hline Age Group & & \\
\hline
\end{tabular}




\begin{tabular}{|l|l|l|}
\hline Youth & 91 & 6.0 \\
\hline Younger adult & 603 & 39.4 \\
\hline Older adult & 618 & 40.4 \\
\hline Aged & 218 & 14.2 \\
\hline Total & 1530 & 100.0 \\
\hline Marital Status & & \\
\hline Married & 1497 & 97.8 \\
\hline Single & 31 & 2.0 \\
\hline Widow & 2 & .2 \\
\hline Total & 1530 & 100.0 \\
\hline Religion & & \\
\hline Muslim & 1119 & 73.1 \\
\hline Christian & 402 & 26.3 \\
\hline Traditionalist & 9 & .6 \\
\hline Total & 1530 & 100 \\
\hline Ethnic group/Tribe & & \\
\hline Tangale & 246 & 16.1 \\
\hline Fulani & 499 & 32.6 \\
\hline Tera & 84 & 5.5 \\
\hline Waja & 200 & 13.1 \\
\hline Other Gombe Tribes & 389 & 25.4 \\
\hline Others & 112 & 7.3 \\
\hline Total & 1530 & 100 \\
\hline work, & & \\
\hline
\end{tabular}

Source: Field work, 2008

Parents' Residential Sectors (Urban/Rural)

Selection by residential sectors (urban and rural) shows that the rural sector dominates by having over 7 in 10 and the urban sector has only less than 3 in 10 (Table 2). This selection became necessary as a result of the fact that constraints facing effective birth registration especially the geographic ones are more serious in the rural areas than in urban areas as indicated by various studies as well as in the ranking of the registration coverage presented above.

Earlier studies, especially those carried out by ${ }^{[5],[27],[28]}$ and $^{[29]}$ among others indicate that the most obvious geographic constraint to birth registration is the distance to the nearest birth registration facility and therefore rural areas are always disadvantaged.

Parents' Occupational Characteristics

Table 2 below portrays the respondents by their occupational types. Farming leads with highest percentage, followed by civil service, trading and other occupations. This shows that larger part of the population especially the rural is made up of farmers.

\section{Parents' Residential Ownership Status}

Table 2 shows that three-quarters of the respondents reside in their own houses, about 1 in 10 live in

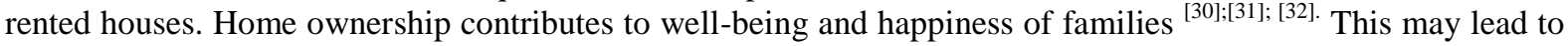
acquiring of other basic needs human rights such as the registration of their children's birth.

Parents' Educational Type and Level

Table 2 shows that about 3 in 10 received Islamic education and over 4 in 10 had received western education and about 2 in 10 did not indicate anything. It is largely assumed that educational type (western or Islamic) of parents can determine birth registration. The Table further indicates the percent distribution of respondents by level of education. It is shown in the table that, out of the ones that attended school about onethird received primary, almost half received secondary school education, tertiary (more than 1 in 10) and adult education was the least at the period of the survey. This shows that although most of them are farmers majority of them received secondary education. 
Parents' Geopolitical Zones of Origin

Table 2 shows that, by geopolitical zone of origin almost three-quarters of the respondents are indigenes of north-east geopolitical zone including Gombe state which alone has over 8 in 10, while north-west, north central and south-west and south-east followed.

TABLE 2: Socio-Economic Characteristics of Respondents

\begin{tabular}{|c|c|c|}
\hline Residence/Sector & Frequency & Percent \\
\hline Urban & 413 & 27.0 \\
\hline Rural & 1117 & 73.0 \\
\hline Total & 1530 & 100.0 \\
\hline \multicolumn{3}{|l|}{ Occupation } \\
\hline Farming & 976 & 63.8 \\
\hline Civil Service & 225 & 14.7 \\
\hline Trading & 213 & 13.9 \\
\hline Others & 116 & 7.6 \\
\hline Total & 1530 & 100 \\
\hline \multicolumn{3}{|c|}{ Residential Ownership Status } \\
\hline Rented House & 163 & 10.7 \\
\hline My own house & 1348 & 88.1 \\
\hline Others & 19 & 1.2 \\
\hline Total & 1530 & 100.0 \\
\hline \multicolumn{3}{|l|}{ Level Of Education } \\
\hline Primary & 209 & 30.4 \\
\hline Secondary & 331 & 48.1 \\
\hline Tertiary & 144 & 15.5 \\
\hline Adult Education & 4 & .6 \\
\hline Total & 688 & 100 \\
\hline \multicolumn{3}{|l|}{ Type of Education } \\
\hline Islamic Education & 538 & 35.2 \\
\hline Western Education & 661 & 43.2 \\
\hline Not Applicable & 331 & 21.6 \\
\hline Total & 1530 & 100.0 \\
\hline \multicolumn{3}{|c|}{ States of origin(Geo. Pol. Zone) } \\
\hline North-East & 1341 & 87.6 \\
\hline North-West & 165 & 10.8 \\
\hline North-central & 8 & .5 \\
\hline South-West & 7 & .5 \\
\hline South-East & 9 & .6 \\
\hline Total & 1530 & 100 \\
\hline
\end{tabular}

Source: Field work, 2008

\subsection{Influence of Parents' Socio-Economic and Demographic Characteristics on Birth Registration}

To achieve one of the objectives of this study, birth registration (dependent variable) was crosstabulated with different background characteristics of the respondents (independent variables) and the use of chi square test was employed for further analyses. This section therefore explores the relationships between birth registration rates and each of the selected socio-economic and demographic characteristics of parents/care givers. A table indicating the Percentage Points of the $\chi^{2}$ Distributioncurled from ${ }^{[33]}$ was used for comparison of the observed and calculated values. Association between the aforementioned respondents' characteristics and birth registration are discussed below:

TABLE 3: Results of Chi-Square Tests Conducted on the Relationship Between Parents' Socio-Economic and Demographic Characteristics and Birth Registration

\begin{tabular}{|l|l|l|l|}
\multicolumn{5}{|c|}{ and Demographic Characteristics and Birth Registration } \\
\hline Parents' characteristics & $\mathbf{X}^{\mathbf{2}}$ & DF & P-Value \\
\hline Sex & $\mathbf{0 . 5 0}$ & $\mathbf{1}$ & .823 \\
Age & $\mathbf{4 3 . 9 7 8}$ & 3 & .000 \\
Marital Status & $\mathbf{. 6 3 5}$ & 2 & .728 \\
Religion & $\mathbf{2 4 . 2 9 9}$ & 2 & .000 \\
Ethnic Group & $\mathbf{7 1 . 1 8 4}$ & 5 & .000 \\
Geopolitical Zone & $\mathbf{4 6 . 4 6 5}$ & 4 & .000 \\
Occupation & $\mathbf{3 2 1 . 7 3 2}$ & 3 & .000 \\
Residential Ownership & $\mathbf{6 4 . 2 1 7}$ & 2 & .000 \\
Type of Education & $\mathbf{1 . 5 7 7}$ & 1 & .000 \\
Level of Education & $\mathbf{7 1 . 0 3 0}$ & 3 & .000 \\
Spouses' Educational Status & $\mathbf{3 8 . 5 8 2}$ & 3 & .000 \\
Sch. Attendance by Children & $\mathbf{7 8 . 6 6 2}$ & 1 & .000 \\
\hline
\end{tabular}




\section{Influence of Residential /Sector (Urban and Rural) on Birth Registration}

$H_{0}=$ Ever obtained birth certificate from NPC does not depend on Residence (sector)

$\mathrm{H}_{\mathrm{A}}=$ Ever obtained birth certificate from NPC depends on Residence (sector)

Criteria: The $\chi^{2}$ calculated (54.226) is $>$ the $\chi^{2}$ tabulated (3.84) at 95\% level of significance and 1 degree of freedom. We therefore, reject the $H_{0}$ and accept $\mathrm{H}_{\mathrm{A}}$ hypothesis. Thus, in table 3 , the $\chi^{2}$ result indicates that there is significant difference between parents' residential sectors and influence on birth registration.

Cross tabulation of the results demonstrates that urban area has 4 in 10 of its study population while rural area has only 2 in 10 that have obtained certificates from the National Population Commission for their children.

Rural areas are found to be having lesser coverage of birth registration than urban areas by some researchers. In Tanzania for instance, the rural registration rate of just 3\% compared to an urban rate of $22 \%$, while in Indonesia, coverage in rural areas is less than half that of urban areas ${ }^{[4]}$. In fact, out of the 63 countries studied by ${ }^{[5]}$, only few countries such as the Democratic Republic of Congo, Guinea-Bissau, Lesotho and Rwanda have higher birth registration rates in the rural areas than in the urban areas as a result of birth registration campaigns and programmes targeting rural areas. In Nigeria the comparative study carried out by ${ }^{[14]}$ and ${ }^{[33]}$ indicate that more births were registered in the urban areas than rural areas of Nigeria over the past 7 years. ${ }^{[34]}$ also shows that more births are registered in urban areas (49\%) than in rural areas (22\%).

Even this very survey indicates that, a considerable number of registration centres are located in the urban Gombe area which leaves rural residents disapprotionately unable to fully access these registration centres. There are eleven (11) registration centres in Gombe town ship alone. That is about half of the total number in the state.

Influence of Parents' Sex on Birth Registration

The implication of this result is that the causes of the non registration in terms of sex differential may be the same. Even the $\chi^{2}$ test shows that significant difference does not exist among parents' sex and their effects on birth registration (see table 3). We also accept the $H_{0}$ and reject $\mathrm{H}_{\mathrm{A}}$. The results from cross tabulation indicate that the proportion of males who have never collected certificates of birth is three-quarters, which is almost the same with that of the females.

The assumption that female headed household differs from male headed one in terms of the rate of birth registration as opined by ${ }^{[33]}$ and ${ }^{[5]}$ is therefore not acceptable going by this result.

Influence of Parents' Age on Registration of Birth

The $\chi^{2}$ test indicates that there is significant difference among parents of different age groups in terms of their influence on birth registration. We therefore, reject the $H_{0}$ and accept $\mathrm{H}_{\mathrm{A}}$ hypothesis.

Cross tabulation reveals that over one-third of the older adults, slightly over 2 in 10 of the young adults, almost 2 in 10 of the Aged and less than 1 in 10 of the youth have obtained certificates from the National Population Commission. These differences may not be unconnected with the high fertility rate of the older adults' age group. ${ }^{[35]}$ lamented that, the role of parents' age in determining living conditions conventionally indicates poor living conditions at the younger and older age cohorts and better living conditions at the middle high productive years. The group therefore may be having better living condition and zeal for going to register the births of their children. ${ }^{\left[{ }_{1}\right]}$ in its study however, explained that age is highly a significant variable for whether a child is registered or not and thus children older than one year are significantly more likely to be registered than children who have not yet reached their first birthday.

\section{Influence of Parents' Marital Status on Birth Registration}

The result of the $\chi^{2}$ indicates that there is no significant difference among parents of different marital status in relation to influence on birth registration. We therefore, accept the $H_{0}$ and reject $\mathrm{H}_{\mathrm{A}}$ hypothesis.

Cross tabulation indicates that over one-third of the married heads of households, less than 1 in 10 of the singles and one of the only 2 widows of the widows obtained certificates from the National Population Commission. The population of the former group is however, much larger than the other two groups. This might have affected the result.

Some studies including ${ }^{[36]}$ and ${ }^{[5]}$ indicated that vulnerable children especially those who have lost their parents, children of single mothers and those born to parents who are illiterate living in precarious economic conditions are less registered. And that is the reason why UNICEF is more concern with the registration of the births of children aged 0-5 years, vulnerable and less privileged children.

Influence of Parent's Religion on Birth registration 
The $\chi^{2}$ calculated indicates that there is a significant difference among parents of different religious affiliations and their influence on the registration of the births of their children.We therefore, reject the $H_{0}$ and accept the $\mathrm{H}_{\mathrm{A}}$ hypothesis.

Cross tabulation of birth registration and Religion shows that, of those who obtained birth certificates, 2 in 10 are Muslims, over 7 in 10 are Christians and only remaining .3\% is traditionalists". That shows that the number of Christians that have obtained birth certificates for their children is higher, perhaps because of their higher level of education and enlightenment.

\section{Influence of Ethnicity/Tribe on Birth Registration}

The $\chi^{2}$ test result indicates that there is significant difference among parents of different ethnic groups in terms of registering the birth of their children. We therefore, reject the $H_{0}$ and accept $\mathrm{H}_{\mathrm{A}}$.

As indicated in cross tabulation result, the majority Fulani group has lower level of registered birth (around 1 in 10) as compared to Tangale with over 3 in 10 and Tera with almost half of its sampled population had obtained certificates for their children. This could be attributed to higher educational levels of the two groups and lower educational level for the first group. And that probably explains why the 'others' category which includes the southern Nigerians and educated elites from other parts of the country living in Gombe, Nigeria have larger proportions of almost half of the sampled population registered their children's births.

Ethnicity is one of the variables that are found to be associated with differential birth registration by study carried out by ${ }^{[5]}$. However, it was discovered that the association varies between countries and the group with larger population has higher number registered birth.

Influence of Parents' Geopolitical Zone of Origin on Birth Registration

The $\chi^{2}$ test shows that the parents from different geo political zones of Nigeria resident in Gombe significantly differ in terms of registration of their children. We therefore, reject the $H_{0}$ and accept $\mathrm{H}_{\mathrm{A}}$

Parents' States or geo-political zone plays an important role in birth registration. This is because as shown in the cross tabulation result, although the north-east geo-political zone has larger number of respondents, the percentage of those who registered the birth of their children is only one-quarter as compared to Southwest $(100 \%)$ and Southeast (almost 7 in 10). The reason for the preponderance of the latter over the former could be attributed to the fact they are more educated and more civilized, even in terms of the nationwide comparison of the rate of registration, they always rank higher ${ }^{[34]}$ and ${ }^{[37] .}$

Influence of Type of Occupation of the Respondents on Birth Registration

The $\chi^{2}$ result shows that there is a significant difference among parents of different occupational types in terms of registration of the births of their children. We therefore, reject the $H_{0}$ and accept $\mathrm{H}_{\mathrm{A}}$.

The nature of occupation of parents has been found to have influence on the children's basic needs ${ }^{[37]}$ and hence the tendency of registering their births. Cross tabulation indicates that out of the total percent of the respondents, civil servants rank higher with almost three - quarters of them having their children's births registered, whereas only about 4 in 10 and 1 in 10 of traders and farmer respectively have their children's births registered. Earlier on, studies such as that of ${ }^{[33]}$ indicates that, $49 \%$ of mothers living in the urban area of Gombe, most of whom engaging in secondary and tertiary activities had their children's birth registered, while only $20 \%$ was reported for rural areas where primary activity like farming dominates. ${ }^{[5]}$ shows that in most countries, birth registration is highest among the richest 20 per cent of the population. For example, Tanzania is the country with the greatest disparity between rich and poor. Only 2 per cent of the poorest 20 per cent of children are registered compared to 25 per cent of the richest 20 per cent

As expressed by ${ }^{\left[{ }^{[}\right]}$, there is little information on the characteristics of unregistered children in the industrialized countries. This is perhaps because, according to ${ }^{[6]}$, the vast majority of unregistered children are found in developing countries where primary production system is the mainstay. However, the rates vary widely between countries and between regions. The disparities can be linked to uneven overall development with unregistered children more likely to be among the poor and excluded ${ }^{[39]}$. ${ }^{[34]}$ also reported that children in wealthier house -holds (62\%) are more likely to be registered than those in poorer house- holds (9\%).

Influence of Parents' House Ownership or Renting Status and Registration of Birth

The $\chi^{2}$ calculated shows that there is significant difference among parents of different housing ownership status as regards the registration of children's birth. Table 3 shows that living in a rented house is inversely related to registration of birth from NPC. Thus, it does not depend on Residential/House Ownership. We therefore, reject the $H_{0}$ nd accept $\mathrm{H}_{\mathrm{A}}$ hypothesis.

The table indicates that parents living in rented houses' registration of children's birth is higher by almost 9 in 10 compared to parents living in their own house which is just (1 in 10). Thus, people living in rented houses 
who are non indigenes and mostly civil-servants and traders largely registered their children's birth as compared to those living in their own houses that are mostly indigenes.

A child's family situation including the house being occupied is believed to have an impact on birth registration rate ${ }^{[5]}$. Family of children living in a house owned by them is perhaps more stable residentially and therefore seems to be more concerned with their children's education and other basic needs including their rights ${ }^{[34]}$. However, this study proves contrary to that notion, in terms of birth registration.

It is not surprising that some of the respondents did not register the births of their children since they did not send them to school where birth certificates would be demanded. ${ }^{[5]}$ reached a conclusion by stating that, "main barrier to birth registration is that, it is not universally perceived as a fundamental right and, as a result is given low priority at every level". Table 3 gives the summary of the results and statistical test below shows the influence of the variable (independent) on the dependent variable.

Influence of Type of Education on Birth Registration

The $\chi^{2}$ resultdisplays that parents with different educational types differ significantly in influence on registration of their children's birth. We therefore, accept the $H_{0}$ and reject $\mathrm{H}_{\mathrm{A}}$ hypothesis. Cross tabulation also indicates that, of the respondents with western education, almost half $(45.7 \%)$ have obtained birth certificates for their children, and only $11.9 \%$ of those with Islamic education have done so. An earlier study carried by ${ }^{[5]}$ indicates a similar result. This finding also agrees with ${ }^{[33]}$

Influence of Parents' Level of Education on Birth Registration

Education is the main source of human capital formation and ultimately a curtailed tool for poverty avoidance. It is expected that living conditions of households will vary across different levels of educational attainment, with higher education more likely to predict better living standards [35].

The $\chi^{2}$ result indicates that there is a significant difference among parents with different educational levels and the registration of birth. We therefore, reject the $H_{0}$ and accept $\mathrm{H}_{\mathrm{A}}$. Cross tabulation reports higher birth registration among parents with tertiary $(72.2 \%)$ than those with primary $(26.8 \%)$ and secondary education $(47.1 \%) .{ }^{[5]}$ also showed that even the educational level of mothers significantly influences birth registration.

Influence of Parents' Spouses' Educational Status on Birth Registration

The $\chi^{2}$ tabulated shows that there is significant difference among parents with spouses with different levels of education and influence on birth registration. Table 3 demonstrates that heads of households whose spouses are attending school now rank higher in terms of registering their children's birth.

Households with educated spouses are associated with a significant increase in the registered birth when compared to those with non-educated spouses. According to ${ }^{[5]}$, the educational level achieved by a child's mother has consistently been shown to have significant influence on health and well being of the family. A positive association is also observed between birth registration and mother's education. Thus, significant disparities in birth registration levels exist between children whose mothers received primary level education as compared to those whose mothers received no education. Greatest disparities are witnessed in Tanzania and Zambia. ${ }^{[33]}$ too in his study on Gombe LGA shows that there is strong correlation between mother's education and birth registration. The educational attainment of mothers was observed also to be influencing immunization coverage ${ }^{[38]}$ and therefore it is not surprising if the same happens to birth registration since they are mostly carried in the same place. Table 3 shows the influence of the variable (independent). We therefore, reject the $H_{0}$ and accept the $\mathrm{H}_{\mathrm{A}}$ hypothesis.

Influence of School Attendance by Children on Birth Registration

The $\chi^{2}$ result indicates that there is a significant difference among parents' whose children attend school and those whose children do not attend in influencing birth registration. Reject the $H_{0}$ and accept the $\mathrm{H}_{\mathrm{A}}$ hypothesis.

Children attendance at school is believed to be having influence on the registration of birth as birth certificates are often demanded either for school enrolment or during the course of the study. Cross tabulation reveals that only 3 in 10 of those whose children attend school obtained birth certificates for their children. According to $\left.{ }^{[39}\right]$, the primary schools' Net Attendance Ratios (NARs) in the southern geopolitical zones are much higher than those in the northern zones of north east and north west (41\%) and a similar pattern exists for primary school attendance among children with the highest Gross Attendance Ratios (GARs) in the southern zones and in the north central zone' than in the north-east. Even ${ }^{[5]}$ indicates that birth registration levels are higher among children who attend early childhood education than those who do not. For instance, in Haiti $74 \%$ for those attending versus $84 \%$ for those who are not are registered have been reported. 


\section{Implications Of Results}

From the preceding discussions of the results it has been made clear that almost all the parental socio economic and demographic characteristics significantly influenced birth registration negatively even though there has been awareness of the system by their leaders and representatives as extracted from the interview with them. Thus, the problem could be attributed to non-accessibility, lack of awareness or negligence from the part of the parents especially those in the rural areas, perhaps coupled with the fact the presentation of the birth certificate for school enrolment and hospital admission have not been made compulsory. In fact, only parents' sex and marital status have been found not to have significant influence on birth registration.

It has been stated in the section dealing with the conceptual framework and literature review that a number of factors determine the birth registration of a child, ranging from national to individuals' determinations. However, for the purpose of this study only parents' socio-economic and demographic characteristics are considered.

\section{Conclusion-}

\section{Conclusion And Recommendations}

Based on the objectives considered for this paper and the foregoing results, it is concluded that, different magnitudes of some of the influence of parents'/caregivers' socio-economic and demographic factors among different locations in the study area, and other relevant information relevant to the task of increasing birth registration coverage are sufficiently investigated and discussed. This is crucial in effecting improvement in the birth registration coverage in all the states.

For further investigation there are numerous areas relating to vital registration that can be carried out in addition to the fact that even this study can still be replicated in other states. Only a few number of factors militating against birth registration were considered in this study. Thus, other factors can be incorporated in future studies. For instance, factors such as age at which a child is registered, child's place of birth (Home or Hospital) and choice of a vital registration centre in an area can be studied.

Identifying and analyzing all the factors militating against death, marriages and even migration registrations which form the other aspects of vital registration can also serve as a good study area. In addition, comparative studies of registered birth events between gender and different geopolitical units of the country are worth undertaken.

\section{Recommendations}

i. Establishment of more functional registration centres especially at health centres, coupled with intensive enlightenment campaigns on the importance of birth certificate at the grass root level to be undertaken by all the key stake holders such as Traditional Councils, media, Local Government Officials, Opinion leaders and NGOs among others should be given priority. This would improve the registration coverage.

ii. Related to the above is that, the potential centres should be located at the centroid (geographic centres ) of all the communities, including the rural communities so as to increase accessibility.

iii. Integrating the birth registration system into not only some Immunization Programme Days (IPDs) and Maternal and New Born Child's Health Week (MNCHW) as is being done now but even to routine Immunization and early child educational development programes should be considered being one of the best strategies ${ }^{[40] ; ~[39] ; ~[13] ; ~}$

${ }^{[41]}$. This requires the collaboration of National Population Commission with Ministry of Health Primary Health Care and Ministry of Education, Ministry for LGs and Chieftaincy Affairs, Traditional Councils, Ministry of Information, NGOs and development partners such as UNICEF.

\section{References}

[1]. I.D. Makama, Text of a Press Briefing on the Occasion of the Commencement of the Local Government Sensitization Workshop on Vital Registration for Stakeholders. Abuja, 2006

[2]. National Population Commission Manual on Registration of Births and Deaths. National Population Commission Abuja, Nigeria, 2004.

[3]. National Population Commission, Vital Registration: Operational Guidelines for Deputy Chief Registrars and Heads of Dept. Abuja, 2008)

[4]. UNICEF, "Birth Registration: Right from the Start", Innocent Digest 9, 2002,

[5]. UNICEF, The 'Rights' Start to Life. A Statistical Analysis of Birth Registration, 2005

[6]. A. Aves Salvador, Making Civil Registration System work better through the Inception of the Barangay Civil Registration System: A Strategic Maneuvering. The $9^{\text {th }}$ National Convention on Statistics (NCS)- (2004).

[7]. Todres, Jonathan, Birth Registration: An Essential First Step toward Ensuring the Rights of All Children. Human Rights Brief, 10(3) 2003, 32-35.

[8]. Lucas, David, Registration, administrative and qualitative data, 2003

[9]. E. Linder Forrest, Methods for measuring population change, Public A Health Service Publication, 1000-series 2(32), 1998.

[10]. World Bank,World, Development Report, (New York: Oxford University Press, 1993). 
[11]. J.B. Olorunsaiye, GIS Application in Health Care Delivery: A Case Study of Hospital Availability and Accessibility in Gombe LGA of Gombe State. Unpublished PGD in GIS submitted to Dept. of Geo-Informatics, Federal School of Surveying, Oyo, 2007.

[12]. National Bureau for Statistics (NBS) (2010). Multiple Indicator Cluster Survey (MICS).

[13]. UNICEF, Report of the Stakeholders' workshop on the Strategy for Massive Birth Registration Held in Kano, Kano State, 2007.

[14]. M. O. Raima, Vital Registration Experiences in Some Developed and Developing Countries. Paper Presented at the National Workshop on Workshop on Vital Registration System in Nigeria Held at the Nike Lake Resort Hotel Enugu from $9^{\text {th }}-11^{\text {th }}$ November, 1993

[15]. Muzzi, Mariana, UNICEF Good Practices in Integrating Birth Registration into Health Systems (2000-2009): Case Studies: Bangladesh, Brazil, the Gambia and Delhi, India. (New York, UNICEF, Jan. 2010).

[16]. J.D. Zubema, Sustainable birth registration system in Nigeria: A paper presented at a workshop organized by the UNICEF "D" Field Office in Crest Hotel, Jos: (22-23 July, 2009).

[17]. V. K. Tewari, 'Improving Access to Services and Facilities in Developing Countries', International Regional Science Review,15(1), 1992, 25-37

[18]. O. Ayeni, A vital registration model for Nigeria: population data assessment in Nigeria. Population Association of Nigeria's proceedings:(1), 1980, 77-86.

[19]. L.O. Enukora, Vital Registration: An Instrument for Development Planning and Administration at the Local Government level. A Paper Presented at One Day Seminar on the Role of Vital Registration in Complementing the Rights of the Child in the New Millennium, Kaduna, July, 2000.

[20]. P. J. Taylor, Quantitative Methods in Geography: An Introduction to Spatial Analysis, Boston: Houghton, S. Miffin., 1977.

[21]. R. W. Thomas, and R.J.Hugget, Modeling in geography, (Barnes and Noble Books, Totowa, New Jersey, USA1980).

[22]. E. Burt, James. And M. Barber, Gerald,. Elementary statistics for geographers.(New York, The Guilford Press, 1996,

[23]. J. Mba Chuks, Reliability of age-sex data in demographic analysis: An assessment of Nigeria' empirical evidence. Ibadan Journal of Social Science, 4 (2), 2006, 89-102.

[24]. Coulton, Claudia J. (1998). Vital records: a source for neighborhood indicators .National neighborhood indicators partnership. The Urban Institute.

[25]. J.E. Archer and T.H. Dalton, The fieldwork in geography. (Batsford, 1968)

[26]. K. Horward, and J. A. Sharp, The management of a student research project.(Gower Publishing Company Ltd UK, 1989,

[27]. C. Duze, Mustafa, Vital Registration in selected developed and developing cSountries. Journal of Social and Management Studies (JOSAMS), Vol. 2, 1995, 27-35.

[28]. United Nations, Principles and Recommendations for a Vital Registration System. Econ.and Social Affairs Statistical Division: 2001, Review 9.

[29]. I.F. Megbolugbe, and P.D Linneman,.Home Ownership Urban Studies, 1993, 30:659-682.

[30]. C. Montgomery, Douglas,. Design and analysis of experiments. $\left(5^{\text {th }}\right.$ Edition.New York, John Wiley and Sons Inc. 2001)

[31]. M. Montgomery, M. Gragnolati, K. Burke, and E. Paredes Measuring living standards with proxy variables. Demography, 2000, 37(2): 155-174

[32]. Maigari, Jude Y. (2007). GIS application in assessing existing birth registration centres in Gombe LGA. Unpublished PGD in GIS submitted to Dept. of Geo-informatics, Federal School of Surveying, Oyo.

[33]. National Population Commission (NPC)[Nigeria] and ICF Macro (2009). Nigeria Demographic and Health Survey (NDHS) 2008: Abuja, Nigeria.

[34]. B. U. Mberu, "Internal Migration and Household Living Conditions in Ethiopia" Demographic Research, 2006, 14 (21): $509-540$

[35]. B. Salawu, Strengthening Vital Registration Systems as Source of Demographic Data for Effective Socio-Economic Development Planning in Nigeria in, Pakistan Journal of Social Sciences, 2009, 6(4): 200-206. Medwell. Journal.

[36]. National Bureau for Statistics (NBS) (2007). Multiple Indicator Cluster Survey (MICS).

[37]. A. K. Monguno, Determinants of childhood immunization coverage inBorno State. An Unpublished PhD Thesis submitted to Dept. of Geog. BUK, 2011..

[38]. National Population Commission (Nigeria) and RTI International (2011). Nigeria DHS EdData Survey: Education Data for Decision-making (2010). Washington DC, USA.

[39]. UNESCO: African workshop on Strategies for Accelerating the Improvement of Civil Registration and Vital Statistics Systems.(Addis Ababa, Ethiopia: $5^{\text {th }}-9^{\text {th }}$ December, 1994).

[40]. K. Bathia, Jayant, 'Situation analysis report' on the status of VRS inKano State Submitted to National Population Commission, 2007. 